\title{
A Smart Firefighting Robot System (LAHEEB)
}

\author{
Yousef Samkari ${ }^{1 *}$, Mowffaq Oreijah ${ }^{1}$, Kamel Guedri ${ }^{1}$, \\ ${ }^{1}$ Mechanical Engineering Department, Umm Al-Qura University \\ Makkah, Saudi Arabia \\ *josephsamkari@gmail.com
}

Abstract- The motivation behind this project is that firefighter's death. Many firefighters are struggling to perform their duty which causes much death while on a mission and the circumstances related to each incident. Firefighters are our heroes and our sense of security in times of trouble. They put themselves on dangerous situations to protect us. At present, the world is moving toward the use of technologies software and hardware. This paper proposed a smart firefighting robot system (LAHEEB) which designed to detect the source of fire, extinguish it and increase the knowledge about fire behavior from incident area. This Robot can extinguish different types of fire $\mathrm{A}, \mathrm{B}, \mathrm{C}, \mathrm{D}, \mathrm{F} / \mathrm{K}$, electric and metal fire without spreading in the shortest time. This robot will reduce the risk of injury for firefighters and possible victims and decrease the monetary losses which increase considerably as fire duration increases. LAHEEB consists of the ultrasonic sensor mounted on a servo motor for obstacles detection and equipped with flame sensors for detecting fire. It also makes use of liquid-tank and spray mechanism for extinguishing the fire. The spraying nozzle is mounted on a servo motor to cover maximum area. Liquid-extinguisher is pumped from the main tank to the nose with the help of a $12 \mathrm{~V}$ pump. The whole system is programmed using an Arduino UNO board (ATmega328P microcontroller) which forms the brain of the system.

Keyword- Robot, Firefighting, Extinguishing, DC motors, Flame sensors, Pumps, Arduino.

\section{INTRODUCTION}

A robot is a machine that perform tasks usually human do it. The first uses of modern robots were in factories as industrial robots. It is a machine with manufacturing tasks, which allowed production without the need for human assistance [1]. The robots divided into several groups such as Tele-robots, Telepresence, Mobile robots and Autonomous robots [1].

Telerobotic or teleportation is a technical name given to any handled device doing operations controlled by the operator, unlike the robots, the Tele-robots are restricted based on how the operator has a limited range of function and commands compare to the robots. Teleoperation known as telepresence, the human operator, has a sense of being on location so that the experience resembles virtual reality. A telepresence robot is similar to a telerobot, and the only difference is providing a data response, such as video and sound. Therefore, telepresence robots commonly used in many fields requiring monitoring procedures, such as child services in nursery and education [2]. The mobile robot is requiring human beings to navigate and carry out tasks [3], while autonomous robots can perform the task independently without the involvement of human beings [4]. Moreover, the industrial robots are multi-function manipulators designed for more specific materials, tools or devices through numerous programmatic drives to perform several tasks [5]. Many studies and projects have shown that robot can be valuable in medicine [6], rescue operation [7, 8], industry [9] and rehabilitation [10-12].

The use of robots is increasing and become more common today than ever before, and the fire extinguisher robot becomes essential to protect human life. The robot can detect and extinguish a fire by its self [13]. There are many projects related to firefighter robotics have been studied through this project to compare, improve, develop the study of the smart firefighting robot (LAHEEB). The following robots are some examples used to fight a fire in different applications, most of them have advantages and disadvantages that helped to improve this study;

Virtual Reality Simulation of Fire Fighting Robot is a system developed in MATLAB/Simulink [14]. It placed for initial testing of control algorithms. This project clearly showed that the robot does not have enough level of functionality, because of low-detailed validation of environment. The robot could operate only in free space without obstacles.

Second robot worked as a firefighting robot in houses, and any municipal buildings called Fire protection Robot. In [15] there is a detailed description of using the absolute time firefighting apprentice which moves in an affiliated speed, analyze the blaze and again extinguish it with the advice of pumping mechanism. The primary system's advantages are detecting fire by complex algorithms, using navigation and using of a sound sensor for activating, while the main disadvantages are a low-efficiency computer, low-power frame, an absence of mapping and return-back. 
Firefighting Robot is a robot that worked only 15 minutes and then returned to the supply station area [16]. This principle is one of the great applications for firefighting that fit in non-industrial buildings such as houses. The main disadvantages are the little period of working time and low storage of water provided.

"Pokey the Fire-Fighting Robot" is the robot that listed for coemption and got improved. In [17] there is a detailed description of basic algorithms of operating and the user equipment. The robot equipped with sensors such as a line-sensor, but it does not work very well in a dense smoke area. The advantages of this robot are using of complex firefighting tool and two types of fire sensors. On the other hand, the disadvantages are working in a short distance paced on the sensors range less than $1.5 \mathrm{~m}$, also the absence of optical means of environment perception and low efficiency of the computer.

In this paper, a smart firefighting robot (LAHEEB) proposed because firefighters play a significant rule in societies therefore many studies are discussed on the use of robots to minimize firefighters' injuries and losses as well as increasing efficiency, safety, and quality of the task and its procedures [18]. The primary function of this robot is to detect the source of different types of fire, extinguish it and increase the knowledge about fire behavior from the incident area. There are several existing types of vehicles for firefighting at home and extinguish forest fires [19]. By using such LAHEEB robot, fire identification and rescue activities can accomplish with higher security and without placing firefighters at high risk and dangerous conditions.

\section{METHODOLOGY}

In this section, the methodology procedures divided into three parts. All parts were assembled to accomplish the function of detecting fire, extinguish it and increase the knowledge about fire behavior. The first part is the mechanicals design structure of the robot's body. The second part is a hardware implementation of the used parts, while the third is the software design details.

\section{A. Mechanical Design Structure}

SolidWorks software is used to produce a 3D schematic diagram of the Smart Firefighting Robot (LAHEEB) as shown in Fig. 1. Also, 3d Rendering is used to present the diagram in clear view as shown in Fig. 2. The main structure is a 4WD smart robot shield. The overall surface of the chassis body is oxidized and sandblasting. The thickness of the body is $2 \mathrm{~mm}$. The shape of the robot is made from aluminum alloy to protect the electronic circuit. The surface is smooth and no concave-convex. The alloy sheet is resistant to heat of up to $200{ }^{\circ} \mathrm{C}$ [20]. The body of aluminum chassis contains holes that make it easier to mounting of sensors and other mechanical components. The flame sensors and ultrasonic sensor were installed in front of the robot to detect fire immediately and avoid hitting any obstacles. The structure of Liquid-extinguisher tank and the robot shown in Fig. 3.
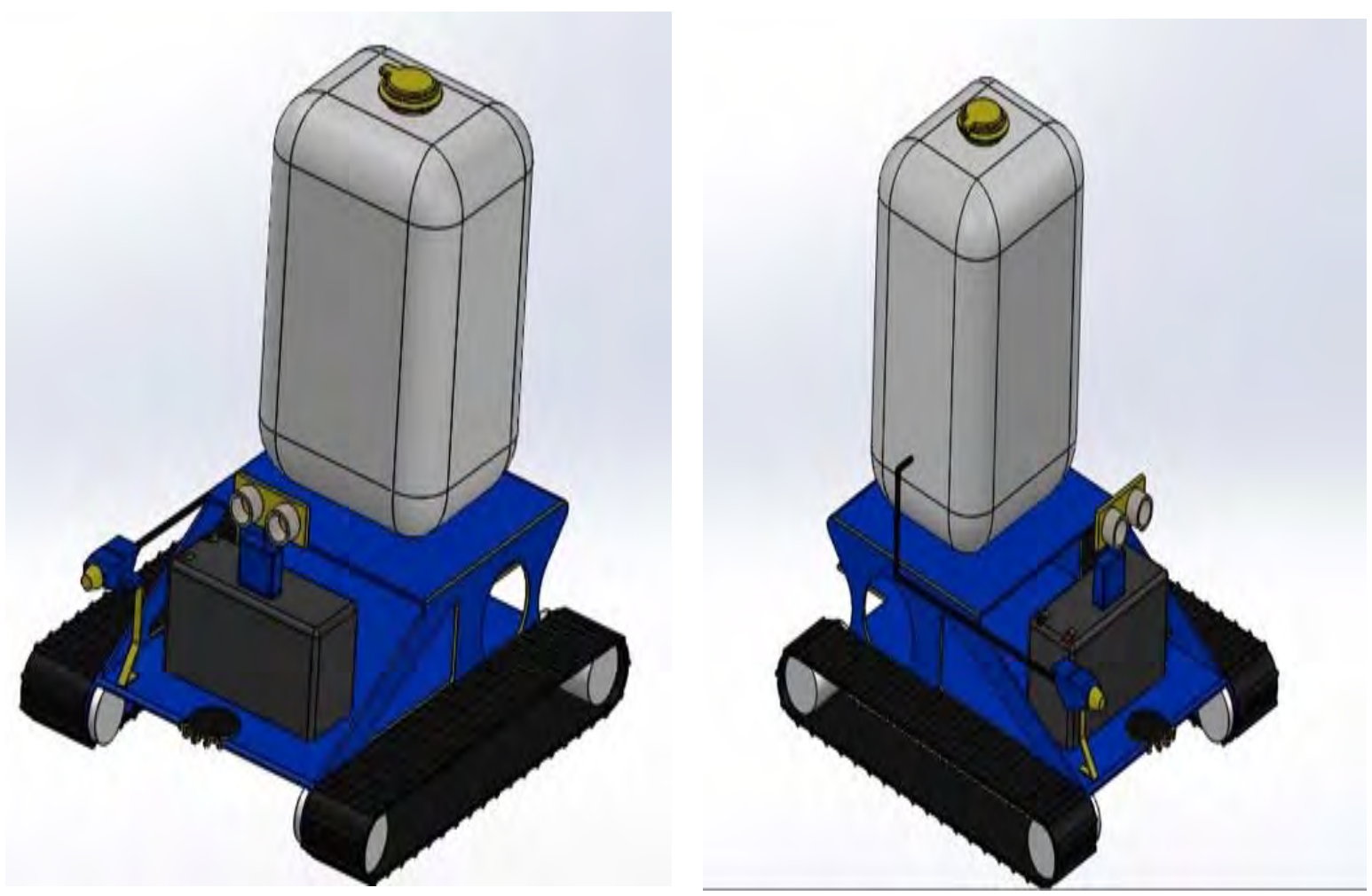

Fig. 1. 3D Structure of LAHEEB using Solidworks Software. 
ISSN (Print) : 2319-8613
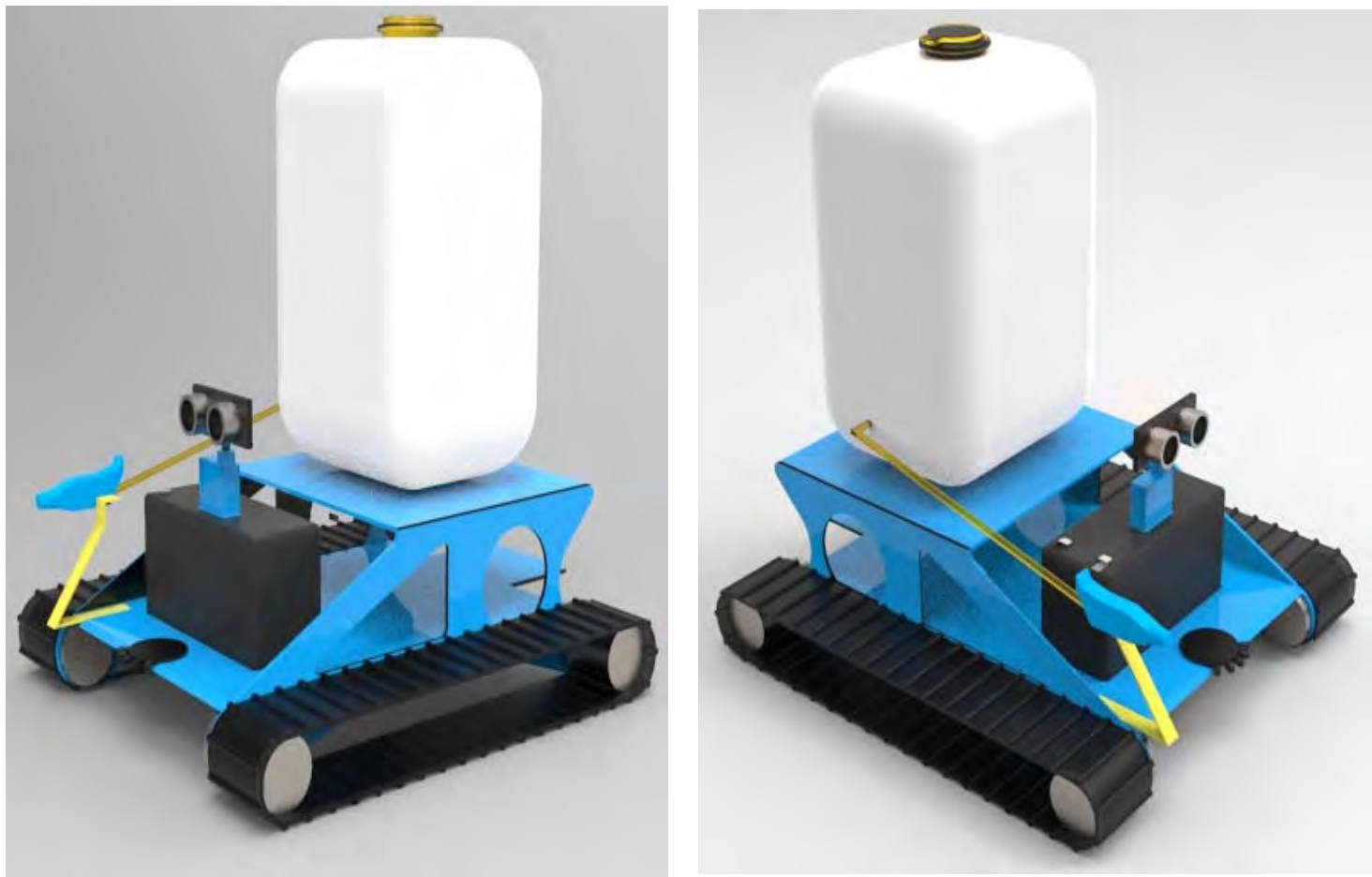

Fig. 2. 3D Structure of LAHEEB using 3D Rendering Software.

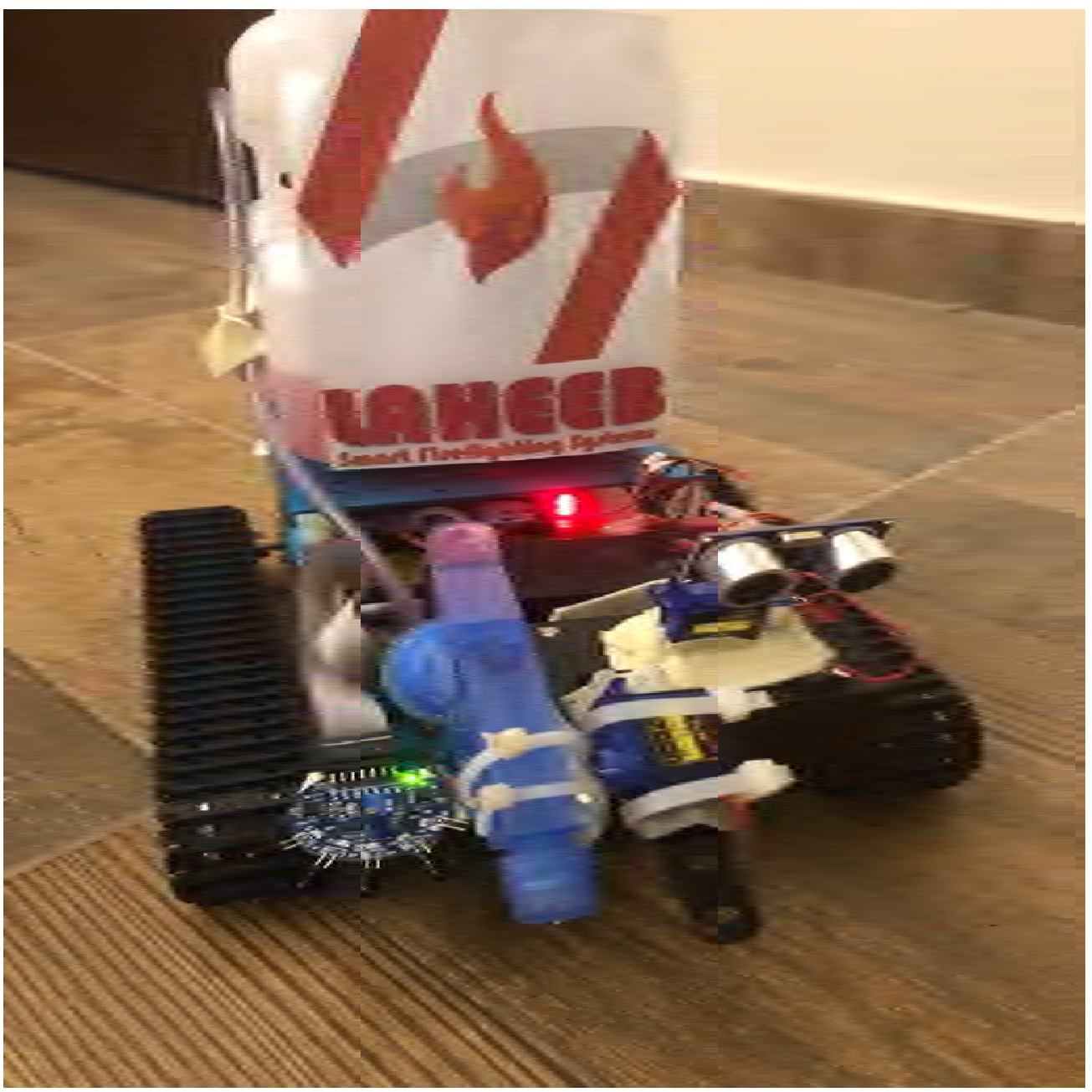

Fig. 3. A Smart Firefighting Robot (LAHEEB). 


\section{B. Hardware Implementation}

There are several parts of electronics that help in developing LAHEEB such as sensors, microcontroller, DC motors, Motor driver, servo motors and pump. Fig. 4 shows the block diagram of LAHEEB process which consists of the input of flame sensor, ultrasonic sensor and temperature sensor, Arduino Uno as the microcontroller, Motor Driver (L293D) and pump to move liquid-extinguisher out of the tank.

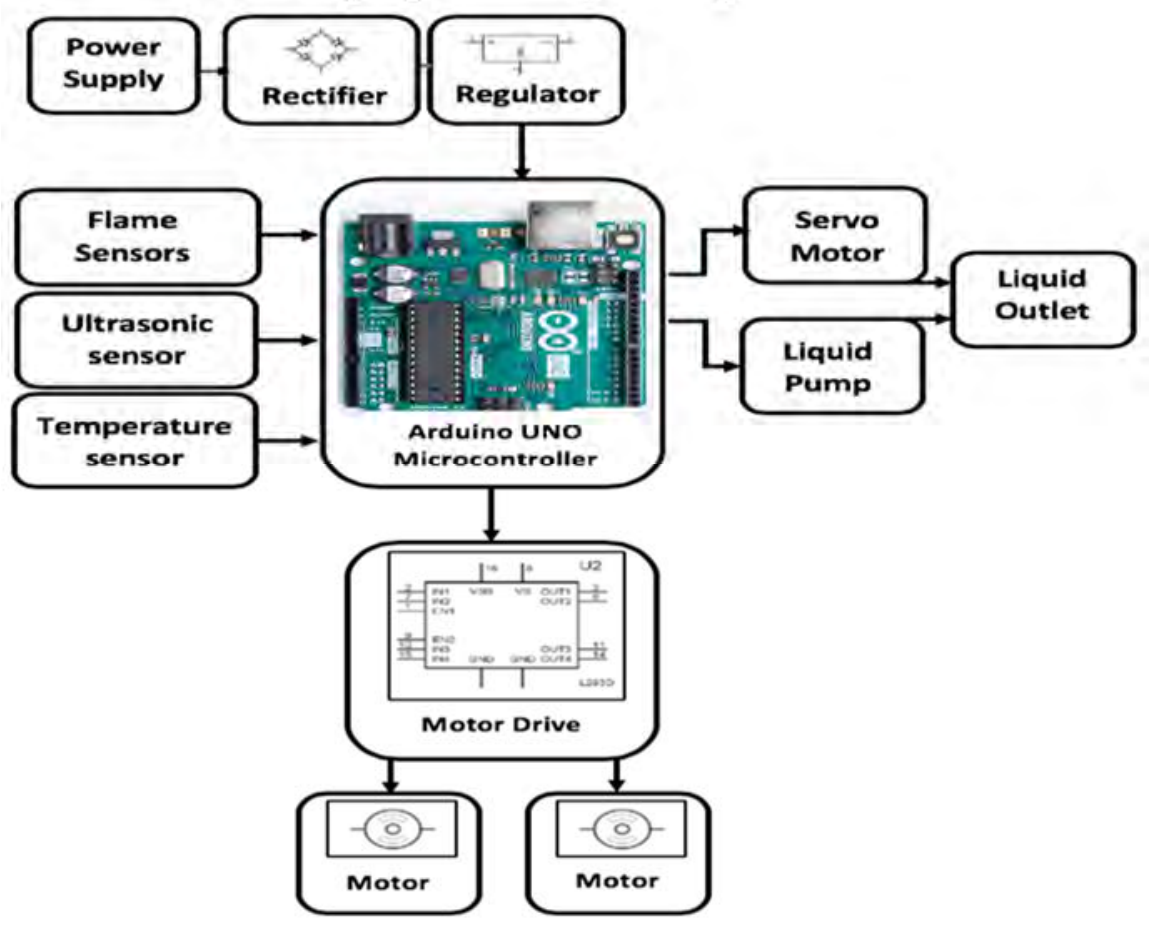

Fig. 4. Block Diagram of LAHEEB.

1) Flame sensors: Five-Channel Flame Sensor Module used in this project to detect flame in the broader area (>120 degrees) as shown in Fig. 5. It identifies the fire with five flame sensors which arranged with 30 degrees. Using 5-channel flame sensor modules is considered an advantage since it has a larger detection angle as well as accurate than the single flame sensor [21]. The working voltage is between 3.3 and $5 \mathrm{~V}$. This module outputs are an analog and digital signal which would be more accurate and easier to use, while potentiometer is used to adjust the digital output sensitivity. The resistors and five LED indicators are making this sensor more precise than other flame sensors.

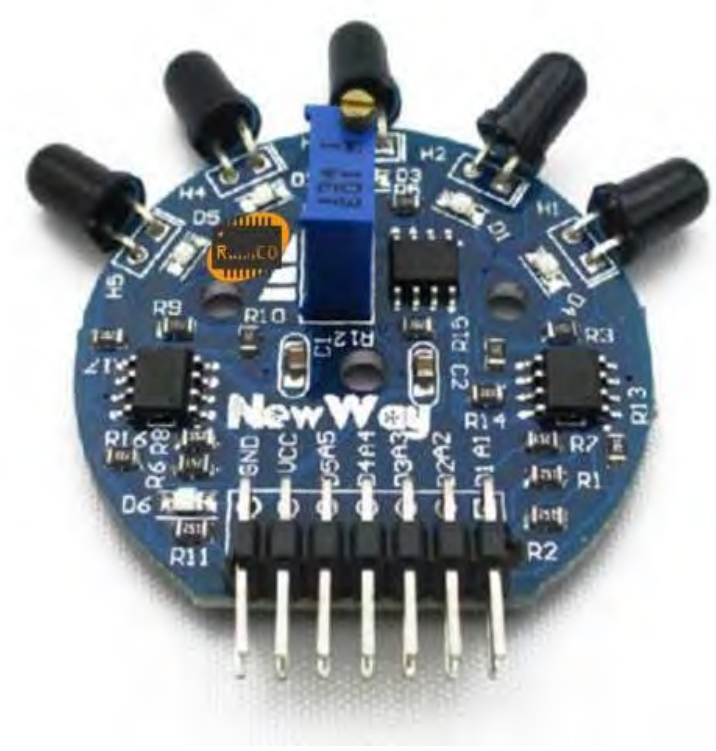

Fig. 5. Five-Channel Flame Sensor 
2) Ultrasonic sensor: One of the most critical electronic parts that provide a very low-cost and easy method of distance measurement as shown in Fig. 6. It used to detect and measure the distance to targets in many automated factories and process plants [22]. To identify the presence of objects sensors with an on or off digital output is required, while sensors with an analog output which varies proportionally to the sensor to target separation distance are commercially available. The HC- SR04 ultrasonic sensor has a range of $2 \mathrm{~cm}$ to $400 \mathrm{~cm}$ with an angle of 15 degrees.

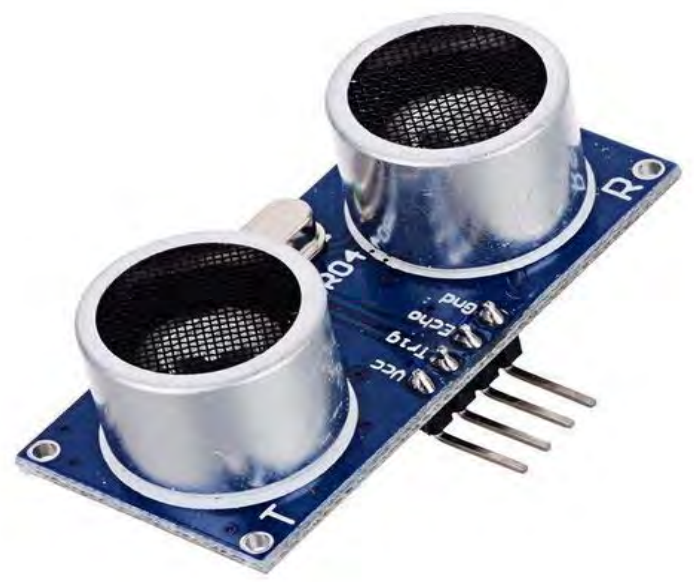

Fig. 6. Ultrasonic Sensor

3) Temperature sensor: The LM335AZ is very easy to use an analog temperature sensor (Fig. 7). It works like a Zener diode with a breakdown voltage proportional to absolute temperature at $10 \mathrm{mV} /{ }^{\circ} \mathrm{K}$. Hook up a resistor from 5V and GND. The LM335A will output an analog voltage of $2.98 \mathrm{~V}$ with $25^{\circ} \mathrm{C}$ or room temperature [23]. The output of the sensor is linear, and when calibrated at $25^{\circ} \mathrm{C}$ the LM335A has less than $1{ }^{\circ} \mathrm{C}$ error over a $100^{\circ} \mathrm{C}$ temperature range typically [23]. The sensor can operate continuously from $-40^{\circ} \mathrm{C}$ to $100^{\circ} \mathrm{C}$. Using this sensor to measure the temperature of the area and gives this information to the control room.

Fig. 7. Temperature sensor. 
4) Servo motors: Servos are used to operate remote-controlled or radio-controlled toy cars, robots, and airplanes. Servo motors controlled by sending an electrical pulse of variable width or pulse width modulation (PWM), through the control wire [24]. A servo motor has 90 degrees in either direction for a total of 180-degree movement.

5) DC motor: A DC motor is an electric motor that runs on direct current (DC) electricity. Usually, DC motors play a significant rule to convert electrical energy into mechanical energy. The two DC motors used in this project for the rotation of the wheel. The working voltage for the DC motor is around $12 \mathrm{~V}$ DC. DC motor is used to move the robot to the fire location [25].

6) Fluid Pump: The Fluid pump is a relevant section in this robot as it will pump fire terminate fluid to extinguish the fire immediately no matter what is the class of fire that occurs. The fluid used because it has a proven certificate for extinguishing all types of fire. A very small-size and light-weight pump is the reason for selecting the pump in this project [26]. The working voltage for this pump is around $4 \mathrm{~V}$ to $12 \mathrm{~V}$, and the working current is $1 \mathrm{~A}$.

\section{Software design details}

Over the years Arduino has been the brain of many projects, from primary objects to complex scientific instruments [27]. Arduino Uno used in this project for programming as shown in Fig. 8. For programming the microcontrollers, the Arduino provides an integrated development environment (IDE) based on Processing language among with $\mathrm{C}$ and $\mathrm{C}++$ languages. Arduino is used in this project because inexpensive, cross-platform in many operating systems, simple, easy programming environment and it has an open source Arduino IDE which makes it easy to write code and upload it to the board.

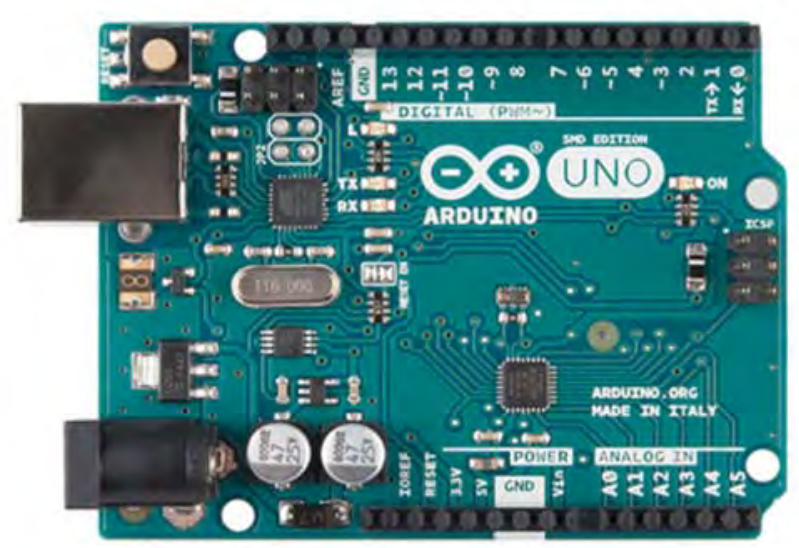

Fig. 8. Arduino Uno microcontroller.

\section{RESULT AND DISCUSSION}

A smart firefighting robot (LAHEEB) has been developed and successfully can detect the source of fire, extinguish it and increase the knowledge about fire behavior from incident area. LAHEEB can find the source of fire by using a five-channel flame sensor and ultrasonic sensor. The flame sensor used to detect fire and its location while the ultrasonic sensor used to detect the obstacles around the robot in order to avoid them. The procedure of the robot in detecting is described clearly in the flowchart of smart firefighting robot (LAHEEB) as shown in Fig. 9. Also, the temperature sensor used to detect the temperature of the area in order to have much accurate results from the incident area. All sensors are connected to Arduino UNO among with pump and two DC motors to control the movement of the robot. If the five-channel flame sensor detects the fire, the DC motor will stop at 30 $\mathrm{cm}$ from the fire. The pump will start to react to push the fire terminator fluid in the source of the fire. 


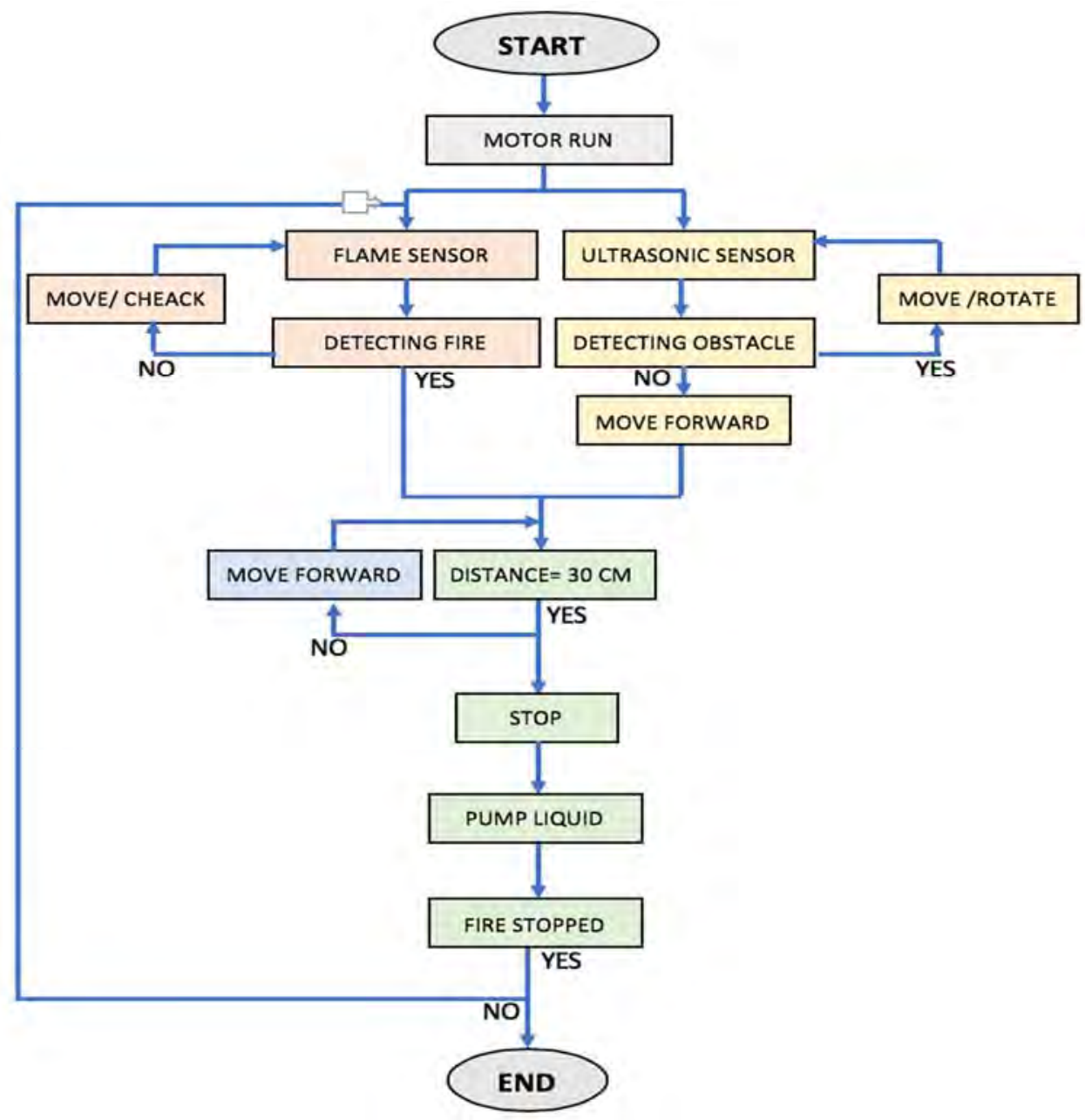

Fig. 9. Flowchart of Smart Firefighting Robot (LAHEEB).

In this paragraph, the discussion will be about the time that takes LAHEEB to reach the source of fire and extinguish it depends on the distance. The following TABLE I shows different experimental scenarios of the robot in extinguishing fire depends on the relation of distance and time.

TABLE I: Time to extinguish fire depends on distance.

\begin{tabular}{|c|c|c|}
\hline Experiment & Time of extinguish the fire (s) & Distance from fire $(\mathrm{cm})$ \\
\hline 1 & 6 & 130 \\
\hline 2 & 5 & 110 \\
\hline 3 & 4 & 90 \\
\hline 4 & 3 & 80 \\
\hline 5 & 2 & 70 \\
\hline
\end{tabular}

The experiment shows the relation of distance to time, and how could the robot work in a different situation. Time is one of the essential things in extinguishing the fire. Therefore, if the robot can put out a fire as quick as possible, that will help in saving victims and reduces losses. The size of the fire is sometimes described as doubling every minute. If the size of such a fire were plotted on a graph, it would create a curved line like the one shown in Fig. 10. 


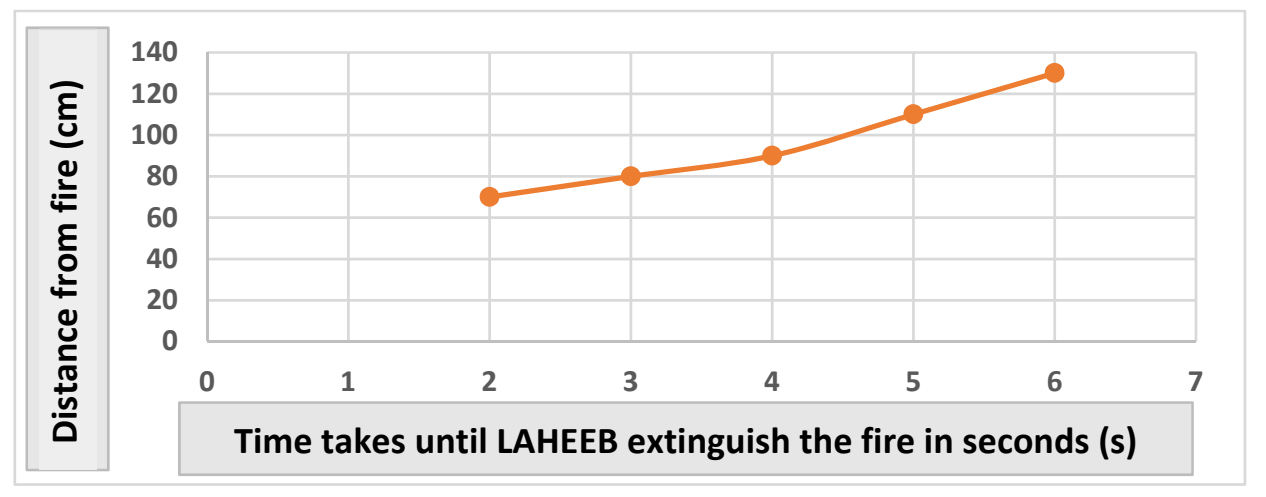

Fig. 10 The relation of time and distance between fire and LAHEEB robot.

\section{CONCLUSION}

From the experimental results, a smart fire-fighting robot (LAHEEB) has achieved its aim and objective successfully. The robot developed to help firefighters in their duty. It has advantageous features such as the ability to detect the source of fire, extinguish it and increase the knowledge about fire behavior from the incident area. This robot can extinguish different types of fire A, B, C, D, F/K, electric and metal fire without spreading in the shortest time. This robot will reduce the risk of injury for firefighters and possible victims and decrease the monetary losses which increase considerably as fire duration increases. LAHEEB also can avoid hitting obstacles or surrounding objects by using sensors. The robot can be used in a place that has a small entrance or in small spaces because it has a compact structure.

\section{REFERENCES}

[1] RobotShop Distribution Inc. "History of Robotics: Timeline." 2008.

[2] Tanaka, F., et al., "Telepresence robot helps children in communicating with teachers who speak a different language", Proceedings of the 2014 ACM/IEEE international conference on Human-robot interaction, ACM: Bielefeld, Germany, pp. 399-406, 2014.

[3] Harik, E.H. and A. Korsaeth, "Combining Hector SLAM and Artificial Potential Field for Autonomous Navigation Inside a Greenhouse", Robotics, 7(2), pp. 22, 2018.

[4] Singh, Harbhinder. "Design and Development of an Autonomous Robot BOOK", 2019.

[5] J. Lee, et al., "Industrial robot calibration method using denavit - Hatenberg parameters", 17th International Conference on Control, Automation and Systems (ICCAS), pp. 1834-1837, 2017.

[6] Jeelani, S., et al., "Robotics and medicine: A scientific rainbow in hospital. Journal of Pharmacy \& Bioallied Sciences", 7(Suppl 2): p. S381-S383, 2015.

[7] Yusof, M., and Dodd, T., "Pangolin: A Variable Geometry Tracked Vehicle With Independent Track Control", Field Robotics, pp. 917924, 2012.

[8] C. Xin, et al., "Design and Implementation of Debris Search and Rescue Robot System Based on Internet of Things", International Conference on Smart Grid and Electrical Automation (ICSGEA), pp. 303-307, 2018.

[9] Day, C.-P., "Robotics in Industry-Their Role in Intelligent Manufacturing", Engineering, 4(4), pp. 440-445, 2018.

[10] Aliff M, et al., "Simple Trajectory Control Method of Robot Arm Using Flexible Pneumatic Cylinders", Journal of Robotics and Mechatronics", 27(6), pp. 698-705, 2015.

[11] Aliff M, et al., "Control and analysis of simple-structured robot arm using flexible pneumatic cylinders", International Journal of Advanced and Applied Sciences, 4(12), pp. 151-157, 2017.

[12] Aliff M, et al., "Control and analysis of robot arm using flexible pneumatic cylinder", Mechanical Engineering Journal, 1(5), pp. DR0051-DR0051, 2014.

[13] Abhilash Dhumatkar, et al., "Automatic Fire Fighting Robot", International Journal of Recent Research in Mathematics Computer Science and Information Technology, April, 2015.

[14] Joga D., et al., "Virtual Reality Simulation of Fire Fighting Robot", Dynamic and Motion, ICIUS, October 24-26, 2007.

[15] Chris Flesher, et al., "Fire Protection Robot", Final Report, pp. 1-78, 2004.

[16] Myles Durkin, et al., "Firefighting Robot", A Proposal, May 5, 2008.

[17] Gerald Weed, et al., "Pokey the Fire-Fighting Robot", A Logical Design Using Digital and Analog Circuitry, May 11, 1999.

[18] Kim, J.-H., et al., "Feature Selection for Intelligent Firefighting Robot Classification of Fire, Smoke, and Thermal Reflections Using Thermal Infrared Images", Journal of Sensors, pp. 13, 2016.

[19] R. N. Haksar and M. Schwager, "Distributed Deep Reinforcement Learning for Fighting Forest Fires with a Network of Aerial Robots", IEEE/RSJ International Conference on Intelligent Robots and Systems (IROS), pp. 1067-1074, 2018.

[20] Jiang, Shouchao, et al., "Buckling Behaviour of Aluminium Alloy Columns under Fire Conditions", Thin-Walled Structures, vol. 124 , pp. 523-537, 2018.

[21] HAN NI ZAW and TIN TIN HLA. "Design and Implementation of Automatic Obstacle Avoidance Car Control System", 1st International Conference on Engineering, Communication and Computer Sciences (ICECCS 2018), 2018.

[22] Aliff, M, et al. "Development of Fire Fighting Robot (QRob)", International Journal of Advanced Computer Science and Applications, vol. 10, no. $1,2019$.

[23] Rahman, A. “Assignment on Temperature Sensors", https://doi.org/10.13140/RG.2.2.16747.23844, 2018.

[24] Mohamed Ahmed Ghiet, et al., "ROBOT ARM CONTROL WITH ARDUINO", 10.13140/RG.2.2.10227.53286, 2017.

[25] Ms, Nagesh, et al. "Fire Extinguishing Robot", IIARCCE, vol. 5, no. 12, pp. 200-202., 2016.

[26] M, Rajesvari, et al., "AUTONOMOUS FIRE FIGHTING ROBOT WITH MULTI SENSOR FIRE DETECTION USING ARDUINO", National Conference on Emerging Technologies for Sustainable Engineering \& Management (NCETSEM'18), 2018.

[27] Arduino Uno Rev3, www.arduino.cc/en/Main/ArduinoBoardUno. 